\title{
Antimalarial Effect of the Total Glycosides of the Medicinal Plant, Ranunculus japonicus
}

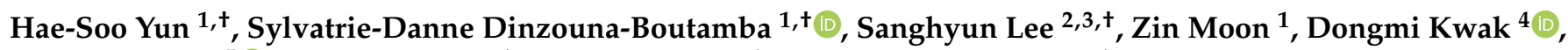 \\ Man-Hee Rhee ${ }^{5}{ }^{\infty}$, Dong-Il Chung ${ }^{1}$, Yeonchul Hong ${ }^{1}$ and Youn-Kyoung Goo ${ }^{1, *}$ \\ 1 Department of Parasitology and Tropical Medicine, School of Medicine, Kyungpook National University, \\ Daegu 41944, Korea; sooandart@naver.com (H.-S.Y.); sylvatriez@yahoo.fr (S.-D.D.-B.); \\ zinmoonkcn@gmail.com (Z.M.); dichung@knu.ac.kr (D.-I.C.); ychong@knu.ac.kr (Y.H.) \\ 2 Division of Zoonotic and Vector Borne Disease Research, Center for Infectious Diseases, Korea National \\ Institute of Health, Korea CDC, Chungbuk 28159, Korea; cdcsanghyun@gmail.com \\ 3 Department of Microbiology, College of Medicine and Medical Research Institute, Chungbuk National \\ University, Cheongju 28644, Korea \\ 4 Laboratory of Parasitology, College of Veterinary Medicine, Kyungpook National University, \\ Daegu 41566, Korea; dmkwak@knu.ac.kr \\ 5 Laboratory of Veterinary Physiology and Cell Signaling, College of Veterinary Medicine, Kyungpook \\ National University, Daegu 41566, Korea; rheemh@knu.ac.kr \\ * Correspondence: kuku1819@knu.ac.kr; Tel.: +82-53-420-4882; Fax: +82-53-420-9330 \\ + These authors contributed equally to this work.
}

check for updates

Citation: Yun, H.-S.; Dinzouna-Boutamba, S.-D.; Lee, S. Moon, Z.; Kwak, D.; Rhee, M.-H.; Chung, D.-I.; Hong, Y.; Goo, Y.-K. Antimalarial Effect of the Total Glycosides of the Medicinal Plant, Ranunculus japonicus. Pathogens 2021, 10, 532. https://doi.org/10.3390/ pathogens 10050532

Academic Editor:

Andrew Taylor-Robinson

Received: 2 April 2021

Accepted: 25 April 2021

Published: 28 April 2021

Publisher's Note: MDPI stays neutral with regard to jurisdictional claims in published maps and institutional affiliations.

Copyright: (c) 2021 by the authors. Licensee MDPI, Basel, Switzerland. This article is an open access article distributed under the terms and conditions of the Creative Commons Attribution (CC BY) license (https:// creativecommons.org/licenses/by/ $4.0 /)$.

\begin{abstract}
In traditional Chinese medicine, Ranunculus japonicus has been used to treat various diseases, including malaria, and the young stem of $R$. japonicus is consumed as a food in the Republic of Korea. However, experimental evidence of the antimalarial effect of $R$. japonicus has not been evaluated. Therefore, the antimalarial activity of the extract of the young stem of $R$. japonicus was evaluated in vitro using both chloroquine-sensitive (3D7) and chloroquine-resistant (Dd2) strains; in vivo activity was evaluated in Plasmodium berghei-infected mice via oral administration followed by a four-day suppressive test focused on biochemical and hematological parameters. Exposure to extracts of $R$. japonicus resulted in significant inhibition of both chloroquine-sensitive (3D7) and resistant (Dd2) strains of $P$. falciparum, with $\mathrm{IC}_{50}$ values of $6.29 \pm 2.78$ and $5.36 \pm 4.93 \mu \mathrm{g} / \mathrm{mL}$, respectively. Administration of $R$. japonicus also resulted in potent antimalarial activity against $P$. berghei in infected mice with no associated toxicity; treatment also resulted in improved hepatic, renal, and hematologic parameters. These results demonstrate the antimalarial effects of $R$. japonicus both in vitro and in vivo with no apparent toxicity.
\end{abstract}

Keywords: Ranunculus japonicus; plasmodium falciparum; plasmodium berghei; antimalarial effect

\section{Introduction}

Ranunculus japonicus is of the tribe Ranunculeae and the family Ranunculaceae. In China and the Republic of Korea, R. japonicus has been used to treat malaria, jaundice, migraines, stomachaches, arthralgia, crane-like arthropathy, ulcers, toothaches, and eye inflammation [1]. The young stem of R. japonicus is known as a food in the Republic of Korea. In addition, the total glycosides of $R$. japonicus showed anti-inflammatory, analgesic, and anti-angiotensin II effects [2,3]. However, experimental evidence of the antimalarial effect of $R$. japonicus has not been evaluated.

Malaria is among the most serious of vector-borne infections; the disease ensues upon transfer of Plasmodium sporozoites from infected Anopheles mosquitoes to human targets [4]. According to the World Health Organization (WHO), half of the world's population is currently at risk for malaria; in 2019, 229 million cases of malaria were reported, with the death toll reaching 409,000 [5]. Malaria remains a major challenge for healthcare providers 
in the developing world; $81 \%$ of the most recent data on malaria cases were from Africa, followed by the regions of Southeast Asia (13\%) and the Eastern Mediterranean (5\%) [6].

Although malaria is a life-threatening disease, it can be controlled with early diagnosis and prompt treatment $[7,8]$. Among the available medications, chloroquine (CQ) was synthesized from quinoline and became the most widely used antimalarial drug by the 1940s due to its low cost and wide range of efficacy $[9,10]$. However, resistance to this drug increased at a rapid rate in Asia, Latin America, and Africa [11,12]. Now, artemisinin- and artemisinin-based combination therapy are used as the first-line treatment for all cases of malaria, especially in regions where Plasmodium falciparum infections predominate [13]. However, the $\mathrm{WHO}$ has reported confirmed cases of artemisinin resistance in five countries in the Greater Mekong Subregion, including Cambodia, the Lao People's Democratic Republic, Myanmar, Thailand, and Viet Nam [14]. Of particular concern, strains of $P$. falciparum isolated from cases of malaria identified at the Cambodia-Thailand border are comparatively resistant to all known effective anti-malarials; as such, there is a real and substantial risk that multidrug resistance will emerge at other locations as well.

As has become clear, antimalarial drug resistance to P. falciparum is an ongoing and increasing problem. In addition to increases in morbidity and mortality, drug resistance has resulted in increased associated costs due to the ongoing efforts to improve the efficacy of antimalarial treatments, which indicates an urgent need for the discovery and development of new antimalarial agents. Medicinal food approaches are clearly feasible and have been beneficial with respect to drug discovery for malaria [15]. As such, we evaluated the antimalarial activity of an extract from the young stem of Ranunculus japonicus (RJE) and the parameters indicating physiopathological changes induced by P. berghei and RJE treatment to reveal the status of infection and therapeutic efficacy of RJE.

\section{Results}

2.1. Antimalarial Impact and Cytotoxicity of the Ranunculus japonicus Extract in Studies Performed In Vitro

As any novel antimalarial drug needs to be effective against both CQ-sensitive and -resistant strains of $P$. falciparum, the impact of the extract prepared from $R$. japonicus was evaluated in an in vitro culture of red blood cells (RBCs) infected with both 3D7 and Dd2 strains. We found that the RJE inhibited parasite growth in a dose-dependent manner; the calculated $\mathrm{IC}_{50}$ values of the 3D7 and Dd2 strains were $6.29 \pm 2.78$ and $5.36 \pm 4.93 \mu \mathrm{g} / \mathrm{mL}$, respectively. The RJE was also tested for potential cytotoxicity against human foreskin fibroblasts (HFFs); the results indicated very low toxicity with high selectivity indices (138.48 for 3D7 and 157.82 for Dd2; Table 1).

Table 1. Antimalarial and cytotoxic activities of Ranunculus japonicus in Plasmodium falciparum 3D7 (chloroquine-sensitive) and Dd2 (chloroquine-resistant) strains.

\begin{tabular}{|c|c|c|c|c|c|}
\hline Compound & $\begin{array}{c}\mathrm{IC}_{50} \text { in } P f 3 \mathrm{D} 7 \\
(\mu \mathrm{g} / \mathrm{mL})\end{array}$ & $\begin{array}{c}\mathrm{IC}_{50} \text { in } P f \mathrm{Dd} 2 \\
(\mu \mathrm{g} / \mathrm{mL})\end{array}$ & $\begin{array}{c}\text { Cytotoxicity } \\
\text { in HFF }(\mu \mathrm{g} / \mathrm{mL})\end{array}$ & $\begin{array}{c}\text { SI } \\
(\mathrm{HFF} / \mathrm{Pf} 3 \mathrm{D} 7)\end{array}$ & $\begin{array}{c}\text { SI } \\
(\mathrm{HFF} / \mathrm{Pf} \mathrm{Dd} 2)\end{array}$ \\
\hline Ranunculus japonicus & $6.29 \pm 2.78$ & $5.36 \pm 4.93$ & $845.89 \pm 13.28$ & 134.48 & 157.82 \\
\hline Chloroquine & $0.005 \pm 0.001$ & $0.40 \pm 0.02$ & $>45$ & & \\
\hline Artemisinin & & $0.002 \pm 0.0009$ & $>70$ & & \\
\hline
\end{tabular}

$\mathrm{IC}_{50}$, the half-maximal drug inhibition concentration; Pf3D7, Plasmodium falciparum chloroquine-sensitive strain; PfDd2, Plasmodium falciparum chloroquine-resistant strain; HFF, human foreskin fibroblast; SI, selective index.

\subsection{Antimalarial Impact of the R. japonicus Extract Used to Treat Mice Infected with Plasmodium berghei}

Because P. falciparum cannot infect mice, the rodent malarial pathogen, P. berghei, was used to evaluate the impact of the RJE in vivo. Parasitemia, body weight, and survival were monitored on days $0-4$ after intraperitoneal inoculation with P. berghei-infected RBCs. Dose-dependent inhibition of parasite growth was observed in the groups of mice that were treated with 200,400, or $600 \mathrm{mg} / \mathrm{kg}$ body weight/day of RJE (RJ200, RJ400, and 
RJ600 groups) at $96 \mathrm{~h}$ post-inoculation (Figure 1A). Specifically, $72.45 \%, 97.50 \%$, and $98.14 \%$ inhibition were observed in RJ200, RJ400, and RJ600, respectively, compared to the level of parasitemia observed among P. berghei-infected mice that did not undergo treatment (NT). The efficacy of RJ400 and RJ600 was comparable with that observed in response to CQ, in which no parasites were detected. Similarly, groups of $P$. berghei-infected mice treated with RJE at 400 or $600 \mathrm{mg} / \mathrm{kg} /$ day gained an average of $1.88 \%$ and $2.46 \%$ of their original body weight at $96 \mathrm{~h}$ post-inoculation (Figure 1B). Increased body weight was also observed in those that had not been infected (NI), the NI400 and CQ groups, but significant reductions were observed among the mice of groups NT and RJ200 (4.71\% and 3.23\% decreases in bodyweight, respectively) at $96 \mathrm{~h}$ post-inoculation. Finally, we found that all mice of RJ400, RJ600, CQ, and NI survived 18 days post-inoculation. By contrast, all mice in the NT control group had died of malaria at day 8 post-inoculation. RJ200 had a $60 \%$ survival rate through day 18 post-inoculation (Figure 1C).
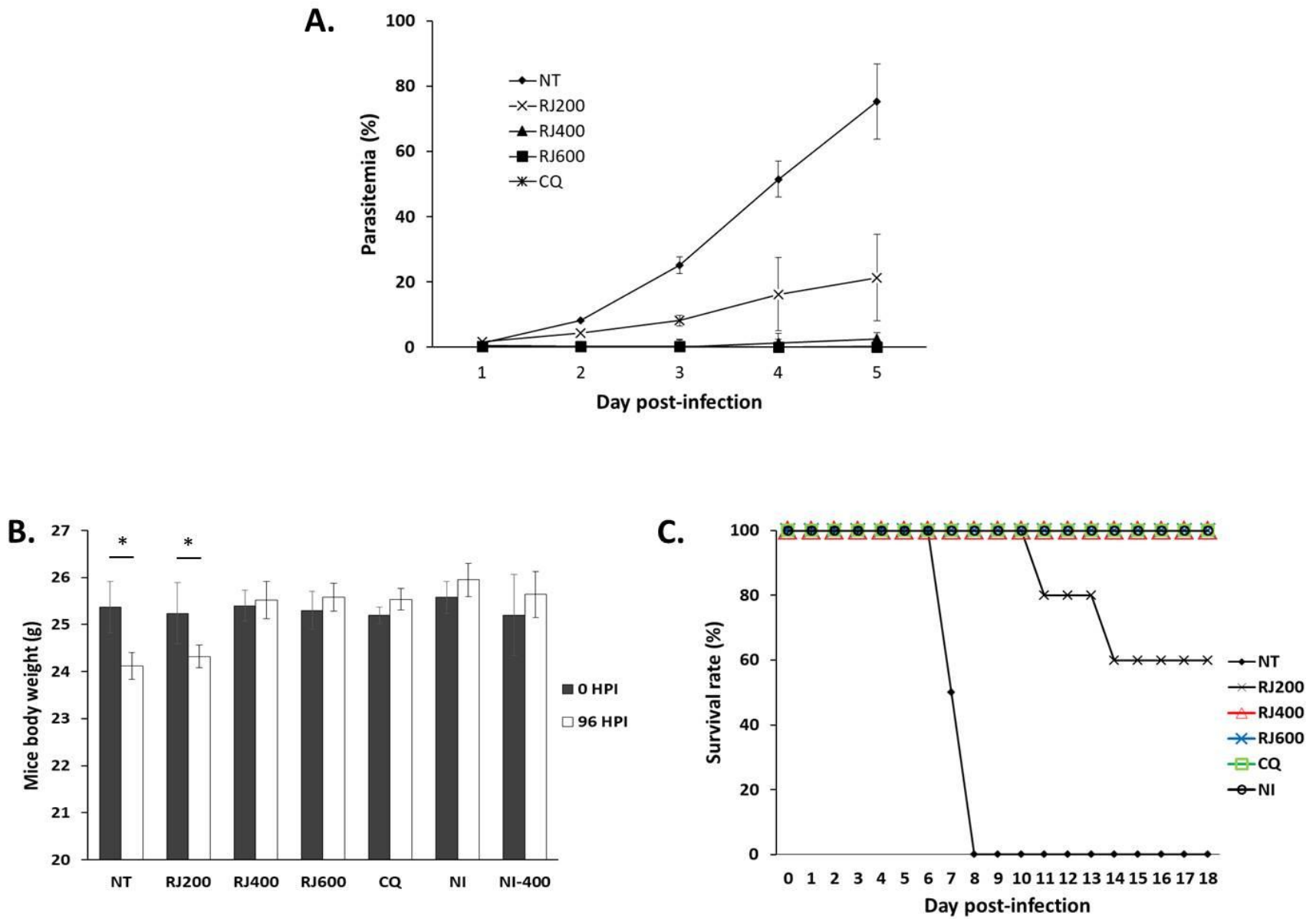

Figure 1. Antimalarial impact of $R$. japonicus extract on parasitemia, total body weight, and survival of $P$. berghei-infected mice. (A) An extract of R. japonicus was administered orally to $P$. berghei-infected mice on four successive days after inoculation; parasitemia was evaluated daily. (B) Total body weights were measured at day 0 and at the end of drug administration for both the NT and five experimental groups. ${ }^{*} p<0.05$ when comparing total body weights at 0 to $96 \mathrm{~h}$ post-inoculation in each of the groups evaluated. (C) Survival was evaluated daily in all groups of mice.

\subsection{Impact of R. japonicus Extract on Hepatic Function of P. berghei-Infected Mice}

As shown in Table 2, high levels of serum aspartate aminotransferase (AST) were detected in the NT group compared to the levels detected for the NI group. On the other hand, significant reductions in serum AST levels were detected in a comparison between mice in the NT group and the experimental groups, except for RJ200. Serum AST levels from mice of RJ400, RJ600, and CQ decreased by $19.6 \%, 20.3 \%$, and $20.8 \%$, 
respectively, compared to that of the NT mice. Moreover, serum alanine aminotransferase (ALT) levels were significantly different when comparing the results of the NT to the NI group. Significant reductions in serum ALT levels by $20.6 \%, 29.5 \%, 29.2 \%$, and $35.4 \%$ were observed for the RJ200, RJ400, RJ600, and CQ groups, respectively, compared to that of the NT controls.

Table 2. Mean values \pm standard deviations of hepatic function parameters in test groups.

\begin{tabular}{cccccc}
\hline & AST (U/L) & ALT (U/L) & $\begin{array}{c}\text { Total } \\
\text { Bilirubin } \\
(\mathbf{m g} / \mathrm{dL})\end{array}$ & $\begin{array}{c}\text { Indirect } \\
\text { Bilirubin } \\
(\mathbf{m g} / \mathbf{d L})\end{array}$ & $\begin{array}{c}\text { Direct } \\
\text { Bilirubin } \\
\text { (mg/dL) }\end{array}$ \\
\hline NT & $61.28 \pm 2.70$ & $35.89 \pm 2.81$ & $1.42 \pm 0.48$ & $0.78 \pm 0.23$ & $0.19 \pm 0.02$ \\
\hline RJ200 & $54.42 \pm 3.12$ & $28.56 \pm 2.85$ & $0.91 \pm 0.05$ & $0.31 \pm 0.09 *$ & $0.42 \pm 0.08$ \\
\hline RJ400 & $50.12 \pm 3.77^{*}$ & $25.23 \pm 1.91 *$ & $0.82 \pm 0.01 *$ & $0.19 \pm 0.02 *$ & $0.74 \pm 0.05^{*}$ \\
\hline RJ600 & $50.13 \pm 2.56^{*}$ & $25.31 \pm 3.20$ & $0.87 \pm 0.01 *$ & $0.19 \pm 0.08^{*}$ & $0.75 \pm 0.04^{*}$ \\
\hline CQ & $50.18 \pm 2.06^{*}$ & $23.13 \pm 2.53 *$ & $0.89 \pm 0.45^{*}$ & $0.19 \pm 0.09 *$ & $0.77 \pm 0.01 *$ \\
\hline NI & $50.13 \pm 1.78^{*}$ & $23.01 \pm 1.42 *$ & $0.77 \pm 0.13 *$ & $0.16 \pm 0.07 *$ & $0.68 \pm 0.03 *$ \\
\hline NI400 & $50.31 \pm 2.24 *$ & $23.21 \pm 0.87 *$ & $0.75 \pm 0.14^{*}$ & $0.17 \pm 0.01 *$ & $0.66 \pm 0.02 *$ \\
\hline
\end{tabular}

* Significant difference $(p<0.05)$ in the hepatic parameters of animals from other groups compared to NT.

Serum levels of total bilirubin and indirect bilirubin were significantly higher in the NT group compared to the levels determined for the NI group. The treated groups revealed $42.5 \%, 46.1 \%$, and $44.4 \%$ declines in total bilirubin in RJ400, RJ600, and CQ, respectively, and $52.6 \%, 76.7 \%, 76.3 \%$, and $78.0 \%$ declines in indirect bilirubin in all groups treated with RJE or CQ, respectively. With respect to levels of direct bilirubin, the levels detected among mice in the NT group were greatly increased compared to those detected for the NI and experimental groups; the levels observed in response to treatment with 200,400, or $600 \mathrm{mg} / \mathrm{kg} /$ day of the RJE and in response to CQ were more than two- to four-fold higher than those observed for the NT group.

\subsection{Impact of the R. japonicus Extract on Renal Function of P. berghei-Infected Mice}

Serum urea and creatinine levels differed significantly when comparing the NT group with the NI group (Table 3). Serum urea levels were significantly reduced by $42.0 \%, 51.8 \%$, $51.3 \%$, and 51.9\% in the RJ200, RJ400, RJ600, and CQ groups, respectively, compared to levels detected in the NT group. Serum creatinine levels were significantly reduced in all treatment groups to $51.9 \%, 65.4 \%, 65.9 \%$, and $67.4 \%$ of the levels detected in the NT, RJ200, RJ400, RJ600, and CQ groups, respectively.

Table 3. Mean values \pm standard deviations of renal function parameters in test groups.

\begin{tabular}{ccc}
\hline & Urea $(\mathrm{mg} / \mathrm{dL})$ & Creatinine $(\mathrm{mg} / \mathrm{dL})$ \\
\hline NT & $68.87 \pm 5.24$ & $3.47 \pm 0.55$ \\
\hline RJ200 & $41.13 \pm 4.25^{*}$ & $1.53 \pm 0.16^{*}$ \\
\hline RJ400 & $33.45 \pm 4.24^{*}$ & $1.21 \pm 0.12^{*}$ \\
\hline RJ600 & $33.63 \pm 2.13^{*}$ & $1.21 \pm 0.08^{*}$ \\
\hline CQ & $33.24 \pm 2.25^{*}$ & $1.18 \pm 0.21^{*}$ \\
\hline NI & $31.348 \pm 1.87^{*}$ & $1.29 \pm 0.19 *$ \\
\hline NI400 & $33.16 \pm 2.84^{*}$ & $1.27 \pm 0.32 *$ \\
\hline
\end{tabular}

* Significant difference $(p<0.05)$ in the renal parameters of animals from other groups compared to NT. 


\subsection{Impact of R. japonicus Extract on Hematologic Parameters of P. berghei-Infected Mice}

The erythrocyte count fell from $9.29 \times 10^{6} / \mu \mathrm{L}$ in NI to $3.19 \times 10^{6} / \mu \mathrm{L}$ in the NT group; the erythrocyte count was significantly higher in the RJ400 and RJ600 groups compared to in the NT group (Table 4). Likewise, the hematocrits of the NT group were reduced by $40.4 \%$ compared to those of the NI. Interestingly, the hematocrits of RJ400 and RJ600 mice were comparable to those of the NI, and the hematocrit values were even higher among those treated with CQ. Hemoglobin concentrations were also reduced by $49.2 \%$ in the NT group compared to the values observed for the NI group. By contrast, hemoglobin concentrations in all mice of RJ400 and RJ600 were comparable to those of the NI group. Likewise, reduced numbers of platelets were observed only in the NT group compared to the NI group, but not in the RJ400 or RJ600 group. By contrast, we detected high platelet counts in the CQ group at $104.1 \%$ of the levels observed for the NI group. Finally, the numbers of total leukocytes, lymphocytes, monocytes, and segmented neutrophils increased in response to infection (NT) (Table 5). Counts in all treated groups except RJ200 were comparable to those of the NI group.

Table 4. Mean values \pm standard deviations of the hematological analysis (hemogram) in the test groups.

\begin{tabular}{|c|c|c|c|c|}
\hline & $\begin{array}{c}\text { Number of } \\
\text { Erythrocytes } \\
\left(10^{6} / \mu \mathrm{L}\right)\end{array}$ & Hematocrit (\%) & $\begin{array}{l}\text { Hemoglobin } \\
\text { (g/dL) }\end{array}$ & $\begin{array}{l}\text { Platelets } \\
\left(10^{3} / \mu \mathrm{L}\right)\end{array}$ \\
\hline NT & $3.19 \pm 0.83$ & $28.89 \pm 5.42$ & $7.45 \pm 1.98$ & $320.24 \pm 27.24$ \\
\hline RJ200 & $4.89 \pm 2.83$ & $33.98 \pm 10.35$ & $11.24 \pm 1.35$ & $543.13 \pm 89.13$ \\
\hline RJ400 & $9.45 \pm 0.89 *$ & $43.13 \pm 5.98 *$ & $14.23 \pm 1.93 *$ & $730.55 \pm 32.13$ * \\
\hline RJ600 & $9.55 \pm 1.42 *$ & $43.13 \pm 1.46^{*}$ & $14.45 \pm 0.98^{*}$ & $763.15 \pm 29.23$ * \\
\hline CQ & $9.79 \pm 0.21 *$ & $47.22 \pm 0.53$ * & $14.98 \pm 0.35 *$ & $793.53 \pm 24.88$ * \\
\hline NI & $9.29 \pm 0.83 *$ & $45.76 \pm 3.13 *$ & $14.66 \pm 0.13 *$ & $734.13 \pm 19.29$ * \\
\hline NI400 & $9.32 \pm 0.99 *$ & $48.13 \pm 2.13$ * & $14.77 \pm 0.01 *$ & $766.75 \pm 24.21$ * \\
\hline
\end{tabular}

* Significant difference $(p<0.05)$ in the hemogram parameters of animals from other groups compared to the NT group.

Table 5. Mean values \pm standard deviations of the hematological analysis (leukogram) in the test groups.

\begin{tabular}{|c|c|c|c|c|}
\hline & $\begin{array}{c}\text { Number of } \\
\text { Leukocytes } \\
\left(10^{3} / \mu \mathrm{L}\right)\end{array}$ & $\begin{array}{l}\text { Lymphocytes } \\
\qquad\left(10^{3} / \mu \mathrm{L}\right)\end{array}$ & $\begin{array}{c}\text { Monocytes } \\
\left(10^{3} / \mu \mathrm{L}\right)\end{array}$ & $\begin{array}{c}\text { Segmented } \\
\text { Neutrophils } \\
\left(10^{3} / \mu \mathrm{L}\right)\end{array}$ \\
\hline NT & $130.24 \pm 14.12$ & $84.13 \pm 6.29$ & $4.13 \pm 0.23$ & $20.99 \pm 7.13$ \\
\hline RJ200 & $43.13 \pm 13.83$ & $33.12 \pm 8.13$ & $2.12 \pm 2.21$ & $14.13 \pm 3.23$ \\
\hline RJ400 & $5.24 \pm 0.48 *$ & $3.24 \pm 0.13 *$ & $0.29 \pm 0.11 *$ & $1.39 \pm 0.47 *$ \\
\hline RJ600 & $5.35 \pm 0.97 *$ & $3.21 \pm 0.11 *$ & $0.25 \pm 0.27 *$ & $1.49 \pm 0.14$ * \\
\hline CQ & $5.21 \pm 0.84$ * & $3.11 \pm 0.83$ * & $0.25 \pm 0.03 *$ & $1.52 \pm 0.89 *$ \\
\hline NI & $5.42 \pm 0.71$ * & $3.33 \pm 0.28 *$ & $0.34 \pm 0.01 *$ & $1.74 \pm 0.88$ * \\
\hline NI400 & $5.27 \pm 0.21 *$ & $3.46 \pm 0.12 *$ & $0.34 \pm 0.01 *$ & $1.71 \pm 0.09$ * \\
\hline
\end{tabular}

* Significant difference $(p<0.05)$ in the leukogram parameters of animals from other groups compared to the NT group.

\section{Discussion}

In a study, Carvalho et al. reported that an extract might be considered as having activity against malaria if one observes a more than $30 \%$ reduction in parasitemia in response to the treatment [16]. As such, our study suggests that the pharmacological 
effects of $R$. japonicus are high; treatment with this extract reduced P. falciparum-associated parasitemia. As shown in Table 1, ethanolic RJE inhibits the growth of both CQ-sensitive and CQ-resistant strains of P. falciparum. Strong inhibition of the P. falciparum Dd2 strain was observed compared with the response of the 3D7 strain; this result suggested that the mechanisms of action associated with this extract are different from those of the previously developed antimalarial agents. Earlier reports suggested that the antiplasmodial activity of natural extracts could be classified as follows: $\mathrm{IC}_{50}<0.1 \mu \mathrm{g} / \mathrm{mL}$, very good activity; $\mathrm{IC}_{50}$ between 0.1 and $1 \mu \mathrm{g} / \mathrm{mL}$, good activity; $\mathrm{IC}_{50}$ between 1.1 and $10 \mu \mathrm{g} / \mathrm{mL}$, good to moderate activity; $\mathrm{IC}_{50}$ between 11 and $50 \mu \mathrm{g} / \mathrm{mL}$, low activity; $\mathrm{IC}_{50}>100 \mu \mathrm{g} / \mathrm{mL}$, inactive [17]. From our data, with an $\mathrm{IC}_{50}$ for strain 3D7 at $6.29 \pm 2.78 \mu \mathrm{g} / \mathrm{mL}$ and for Dd2 at $5.36 \pm 4.93 \mu \mathrm{g} / \mathrm{mL}$, the RJE exhibits good to moderate activity against these target pathogens. Equally importantly, the extract promoted little to no cytotoxicity against human cells (Table 1), and the RBCs underwent no morphological changes when examined in vitro. Using a definition of SI $>10$ as comparatively unharmful, the SIs associated with the RJE ( $>45$ and $>70$, respectively) revealed little to no toxicity to cells in culture [18].

To evaluate the antimalarial impact of $R$. japonicus in an animal model, in vivo experiments were conducted using the P. berghei ANKA strain to infect wild-type mice. Using this model, the extract from $R$. japonicus showed significantly suppressed parasitemia at four days post-inoculation (96 h post-infection; $p<0.05$ ) at rates from $72.45 \%$ to $98.14 \%$ compared to the NT; these findings validate the ethnomedical approach toward malaria management. However, the R. japonicus-treated mice group, especially when used at $200 \mathrm{mg} / \mathrm{kg} / \mathrm{day}$, resulted in weight loss at $96 \mathrm{~h}$ post-inoculation; increased body weight over this same period was observed in NI, CQ, and higher doses of $R$. japonicus. This decrease in body weight paralleled the survival rates; $60 \%$ of mice treated with $200 \mathrm{mg} / \mathrm{kg} /$ day of $R$. japonicus died by day 14 post-inoculation. These results suggested that the antimalarial impact of RJE was not as long-lasting or as effective as CQ in infected animal hosts. These low survival rates might also be due to the reemergence of $P$. berghei parasites after their initial clearance. Similar results with respect to mean survival time have been previously reported [19].

Malaria infection results in several pathophysiological changes due to the complex interactions that occur between the parasite and host. As such, we evaluated the parameters associated with hepatic, renal, and hematological responses to infection to gain a complete understanding of the therapeutic efficacy [20,21]. Treatment with RJE at doses at or greater than $400 \mathrm{mg} / \mathrm{kg}$ /day resulted in significant reductions in parasitemia; we found that parasite density was inversely associated with intact hepatic and renal functions. In P. berghei and P. falciparum infections, severe hepatic damage related to hepatic vessel congestion, periportal infiltration, and sinusoidal dilatation promoted direct changes in hepatic systems, increased the risk of liver failure, and induced metabolic modifications at glycemic levels [22]. The analyses of AST and ALT enzymatic activity and bilirubin concentrations are important markers of hepatic lesions in malaria. Reduced serum levels of AST, ALT, total bilirubin, and indirect bilirubin observed in response to treatment suggest that $R$. japonicus could protect $P$. berghei-infected animals against liver damage, thus improving their clinical status. Moreover, malaria infection also results in renal damage due to alteration of renal blood circulation caused by conformational changes of parasitized erythrocytes, increased blood viscosity, and cytoadherence of infected erythrocytes [23]. The observed decreases in serum levels of urea and creatinine suggest that reductions in parasitemia in response to administration of the RJE may also prevent erythrocyte adherence, high blood viscosity, dysfunctional renal blood circulation, and subsequent renal injury.

Hematological parameters, including RBC count, hemoglobin, hematocrit, platelet counts, and total white blood cell count, are frequently monitored as indicators of drug efficacy in malaria infection settings [24]. Parameters including the RBC count, hemoglobin, and hematocrit are all associated with anemia, which is the most common complication of malaria [25]. Hemoglobin functions in oxygen transport to tissues and promotes the oxidation of ingested food for energy release; it also transports carbon dioxide out of 
the body. Therefore, the hematocrit is an indicator of the ability to transport oxygen and absorb nutrients [26]. RJE treatment led to the restoration of diminished hemoglobin, hematocrit, and RBC counts observed in P. berghei-infected mice. Similarly, we observed an increase in the number of total leukocytes in the peripheral blood in response to infection; these results suggested that the host immune response was functioning in an attempt to combat the parasite [27]. The RJE treatment resulted in a significant reduction in the number of leukocytes recruited in response to infection with $P$. berghei; this may be a direct consequence of the $R$. japonicus-mediated reduction in parasite numbers.

Given its capacity to limit the growth of Plasmodium parasites in vitro and in vivo, RJE remains worthy of further evaluation. Notably, the discovery of the critical drug, artemisinin, began with the observation that an extract of Artemisia annua L. (Qinghao) resulted in only $12 \%$ to $40 \%$ growth inhibition in vitro [28].

\section{Materials and Methods}

\subsection{Preparation of Herb Extracts}

The RJE was prepared by following a previously described method, but with modifications [29]. Briefly, R. japonicus was collected from the Republic of Korea (GPS coordinates, $36^{\circ} 6^{\prime} \mathrm{N} 127^{\circ} 28^{\prime} \mathrm{E}$ ). The air-dried and cut $R$. japonicus was extracted under reflex with $85 \%$ ethanol three times by filtration, pooling, and evaporation. After re-suspension in distilled water and partitioning in a 1:1 ration with ethyl acetate, the water fraction was eluted with water and ethanol by a D-101 macroporous resin column. The ethanol fraction formed the total glucosides of $R$. japonicus. Subsequently, the ethanol fraction was incubated in a rotary evaporator until all of the ethanol had evaporated. The dried extract solubilized in the culture medium or phosphate-buffered saline before experimental use.

\subsection{Cell Cytotoxicity Assay}

Cytotoxicity was evaluated in HFF cultures. Primary HFFs were maintained in Dulbecco's modified Eagle's medium containing 10\% fetal calf serum, 100 units/mL penicillin/streptomycin, and $2 \mathrm{mM}$ L-glutamine. To perform the cytotoxicity assay, cells were seeded in 96-well flat-bottom tissue culture clusters (Merck, Kenilworth, NJ, USA) at $10^{4}$ cells/well and incubated overnight. Cells were then treated with serial dilutions of the test compounds (final concentrations ranging from 10 to $1000 \mu \mathrm{g} / \mathrm{mL}$ ), and cell proliferation was evaluated with the MTT (3-[4,5-dimethylthiazol-2-yl]-2,5-diphenyltetrazolium bromide, Sigma, St. Louis, MO, USA) assay after $72 \mathrm{~h}$ at $37{ }^{\circ} \mathrm{C}$ in $5 \% \mathrm{CO}_{2}$ [30]. The results are expressed as the half-maximal drug inhibition concentration $\left(\mathrm{IC}_{50}\right)$, which is the dose of compound necessary to inhibit cell growth by $50 \%$. Three independent experiments were performed, with each trial performed in triplicate.

\subsection{In Vitro Testing Against Plasmodium falciparum $3 D 7$ and Dd2 Strains}

The culture medium for this experiment included RPMI 1640 medium powder (Merck, USA), 10\% normal human serum (A blood type, obtained from the Korean Red Cross), and $10 \mu \mathrm{g} / \mathrm{mL}$ gentamicin (Invitrogen, Carlsbad, CA, USA). Human RBCs to be infected and P. falciparum strains 3D7 and Dd2 were obtained from the Korean Red Cross and the Malaria Research and Reference Reagent Resource Center (MR4), respectively. Malarial strains were seeded with the medium and RBCs in cell culture plates and then incubated in $90 \% \mathrm{~N}_{2}, 5 \% \mathrm{O}_{2}$, and $5 \% \mathrm{CO}_{2}$ until $2 \%$ parasitemia was reached. Cells were synchronized two times with 5\% D-sorbitol (Sigma, Saint Louis, MO, USA) until only rings had formed prior to addition of the RJE. Concentrations of RJE at 100,75, 50, 25, 10, and $1 \mu \mathrm{g} / \mathrm{mL}$ and CQ at $0.001,0.01,0.1,1$, and $10 \mu \mathrm{g} / \mathrm{mL}$ were prepared. In the case of the P. falciparum $\mathrm{Dd} 2$ strain, $0.001,0.01,0.1,1$, and $10 \mu \mathrm{g} / \mathrm{mL}$ artemisinin was included in the prepared culture. RJEs were added to cultures of synchronized $P$. falciparum parasite-infected RBCs $(100 \mu \mathrm{L}$ to each well in a 96-well plate). After $72 \mathrm{~h}$, parasitemia was evaluated by light microscopy; $\mathrm{IC}_{50}$ values were calculated using Microsoft Excel. Each concentration was evaluated in triplicate and in three independent trials. 


\subsection{Selective Index}

The selective index (SI) is a value that provides a measure of a substance's toxicity to normal human cells compared to its toxicity against a parasite. SIs were calculated as the ratios between the $\mathrm{IC}_{50}$ values for cytotoxicity against HFFs and those calculated for $P$. falciparum strains 3D7 or Dd2.

\subsection{In Vivo Testing Against the Plasmodium berghei ANKA Strain in Infected Mice}

The antimalarial efficacy of the RJE was evaluated using a four-day suppressive test, as previously described [31]. Thirty-six female ICR mice (6 weeks old, weighing $25 \pm 2 \mathrm{~g}$ ) were purchased from Dae Han Bio Link Corporation, Eumsung, South Korea. Mice were randomly assigned into one of six groups, with six mice per group (NT: no treatment after P. berghei infection; RJ200, RJ400, and RJ600: 200, 400, and $600 \mathrm{mg} / \mathrm{kg}$ of RJE treatment after $P$. berghei infection, respectively; CQ: $10 \mathrm{mg} / \mathrm{kg}$ of CQ treatment after $P$. berghei infection; NI: no treatment and no infection; NI400: $400 \mathrm{mg} / \mathrm{kg}$ of RJE treatment without infection). For $P$. berghei infection, a donor mouse was infected with a frozen stock of $P$. berghei and then bled by cardiac puncture. Subsequently, mice that were prepared for inhibition assays were inoculated with $1 \times 10^{6} \mathrm{P}$. berghei (ANKA strain)-infected mouse RBCs prepared from the donor mouse by intraperitoneal injection. These mice were then provided with oral doses of RJE (200, 400, and $600 \mathrm{mg} / \mathrm{kg}$ ) or CQ by gavage; one group was maintained as an NT. Treatment was performed daily for a total of four days. Giemsa-stained smears were prepared from tail-vein blood sampled on days 0 through 4 (i.e., $96 \mathrm{~h}$ post-i.p. inoculation), and were examined under a microscope for quantitative evaluation of parasitemia. The growth inhibition of parasites was evaluated through a comparison with the no-treatment control group and was calculated as follows: Parasite inhibition rates $=100-$ ([parasitemia determined in test group/parasitemia determined in NT group] $\times 100$ ). Body weights and mortality were monitored daily. Experimental monitoring was terminated at 30 days post-infection. All animal experiments were approved by Kyungpook National University Animal Experiment Ethics Committee (Approval No. 2014-0082).

\subsection{Blood Sample Preparation}

For analysis of liver and kidney toxicity, as well as hematological parameters, $100-150 \mu \mathrm{L}$ of blood was collected from the lateral tail vein of the tested mice in tubes with ethylenediaminetetraacetic acid (EDTA) after three days of treatment. Plasma samples for liver and kidney toxicity were prepared under centrifugation for $10 \mathrm{~min}(2000 \times g)$. Whole blood samples for hematological parameter analysis were stored at room temperature, and measurements were performed within $8 \mathrm{~h}$ after blood collection.

\subsection{Liver and Kidney Toxicity}

To evaluate the impact of RJE on hepatic function, the serum levels of aspartate aminotransferase (AST), alanine aminotransferase (ALT), and bilirubin were determined. The tests of renal function included serum levels of uric acid and creatinine. These values were determined using commercial enzyme-linked immunosorbent assay kits according to the manual provided by the company (Cloud-Clone Corp., Wuhan, China) [32].

\subsection{Hematological Parameters}

Complete blood counts were performed after three days of treatment using an automatic hematology analyzer (Celltac, Alpha VET MEK-6550, Nihon Kohden Co, Tokyo, Japan) with Data Management Software (DMS-Lite); these evaluations included erythrocytes, hemoglobin, hematocrit, platelet count, absolute number of leukocytes, lymphocytes, monocytes, and segmented neutrophils. 


\subsection{Statistical Analysis}

The results were presented as means \pm standard deviation. The data were analyzed using ANOVA followed by Tukey's test (GraphPad Prism, San Diego, CA, USA), where $p$ levels of significance $\leq 0.05$, expressed as the mean standard deviation.

Author Contributions: Conceptualization, Y.-K.G. and M.-H.R.; Methodology, Y.-K.G.; Validation, Y.-K.G. and S.L.; Formal Analysis, H.-S.Y., S.-D.D.-B. and Z.M.; Investigation, H.-S.Y. and S.-D.D.-B.; Resources, M.-H.R. and D.K.; Data Curation, Y.-K.G.; Writing-Original Draft Preparation, H.-S.Y.; Writing-Review and Editing, Y.-K.G.; Visualization, S.L.; Supervision, D.-I.C. and Y.H.; Funding Acquisition, Y.-K.G. and S.-D.D.-B. All authors have read and agreed to the published version of the manuscript.

Funding: This research was financially supported by the Basic Science Research Program (NRF2019R1C1C1002170) and Brain Pool program (NRF-2018H1D3A1A02074759) funded by the Ministry of Science, ICT and Future Planning through the National Research Foundation of Korea (NRF).

Institutional Review Board Statement: This study was approved by the ethics committee of Kyungpook National University (KNU 2017-0003). Human red blood cells and serum samples were provided by the Korean Red Cross. All animal experiments were approved by the Kyungpook National University Animal Experiment Ethics Committee (Approval No. 2014-0082).

Informed Consent Statement: Not applicable.

Data Availability Statement: All of the data are present in the manuscript.

Conflicts of Interest: The authors declare no conflict of interest.

\section{References}

1. Xie, Z.W. Compilation of the National Chinese Herbal Medicine; People's Health Publishing House: Beijing, China, $1996 ;$ p. 201.

2. Wang, R.L.; Tan, Y.Z. Effects of ranunculin on angiotensin II-induced myocardial hypertrophy. J. Guangdong Coll. Pharm. 2008, 24, 154-156.

3. Wang, R.L.; Tan, Y.Z.; Luo, S.B. Anti-inflammatory and Analgesic Effect of Total Glycosides of Ranunculus japonicus. Lishizhen Med. Mater. Med. Res. 2009, 20, 290-292.

4. Centers for Disease Control and Prevention: CDC's Malaria Program. 2021. Available online: https://www.cdc.gov/malaria/ resources/pdf/fsp/cdc_malaria_program_2021.pdf (accessed on 3 March 2021).

5. World Health Organization. World Malaria Report 2020. 2020. Available online: https://www.who.int/teams/global-malariaprogramme/reports/world-malaria-report-2020 (accessed on 10 January 2021).

6. Autino, B.; Noris, A.; Russo, R.; Castelli, F. Epidemiology of malaria in endemic areas. Mediterr. J. Hematol. Infect. Dis. 2012, 4, e2012060. [CrossRef] [PubMed]

7. Tse, E.G.; Korsik, M.; Todd, M.H. The past, present and future of anti-malarial medicines. Malar. J. 2019, 18, 93. [CrossRef] [PubMed]

8. Arya, A.; Foko, L.P.K.; Chaudhry, S.; Sharma, A.; Singh, V. Artemisinin-based combination therapy (ACT) and drug resistance molecular markers: A systemic review of clinical studies from two malaria endemic regions-India and Sub-Saharan Africa. Int. J. Parasitol. Drug Resist 2020, 15, 43-56. [CrossRef] [PubMed]

9. Singh, S.K.; Singh, S. A brief History of Quinoline as Antimalarial Agents. Int. J. Pharm. Sci. Rev. Res. 2014, 50, $295-302$.

10. O'Neill, P.M.; Barton, V.E.; Ward, S.A.; Chadwick, J. Treatment and Prevention of Malaria: Antimalarial Drug Chemistry, Action and Use; Springer Science and Business Media: Basel, Switzerland, 2012.

11. Hailemeskel, E.; Kassa, M.; Taddesse, G.; Mohammed, H.; Woyessa, A.; Tasew, G.; Sleshi, M.; Kebede, A.; Petros, B. Prevalence of sulfadoxine-pyrimethamine resistance-associated mutations in dhfr and dhps genes of Plasmodium falciparum three years after SP withdrawal in Bahir Dar, Northwest Ethiopia. Acta Trop. 2013, 128, 636-641. [CrossRef] [PubMed]

12. Vanshika, L.; Manoj, K.D.; Neeru, S.; Vas, D.; Wajihullah, K.; Yagya, D.S. Multiple Origins of Plasmodium falciparum Dihydropteroate Synthetase Mutant Alleles Associated with Sulfadoxine Resistance in India. Antimicrob. Agents Chemother. 2011, 55, 2813-2817.

13. Adan, I.; Ibrahim, Y.; Gasim, G.I. Efficacy and safety of artemisinin-based combination therapy for umcomplicated Plasmodium falciparum malaria in Sudan: A systematic review and meta-analysis. Malar. J. 2018, 17, 110. [CrossRef]

14. World Health Organization. Status Report on Artemisinin and ACT Resistance. 2017. Available online: https://www.who.int/ malaria/publications/atoz/artemisinin-resistance-april2017/en/ (accessed on 4 January 2021).

15. Noronha, M.; Pawar, V.; Prajapati, A.; Subramanian, R.B. A literature review on traditional herbal medicines for malaria. S. Afr. J. Bot. 2020, 128, 292-303. [CrossRef]

16. David, A.F.; Philip, J.R.; Simon, L.C.; Reto, B.; Solomon, N. Antimalarial drug discovery: Efficiency models for compound screening. Nat. Rev. 2004, 3, 509-520. 
17. Krafts, K.; Hempelmann, E.; Skórska-Stania, A. From methylene blue to chloroquine: A brief review of the development of an antimalarial therapy. Parasitol. Res. 2012, 111, 1-6. [CrossRef]

18. Cui, L.; Su, X. Discovery, mechanisms of action and combination therapy of artemisinin. Expert Rev. Anti Infect. Ther. 2007, 7, 999-1013. [CrossRef]

19. Carvalho, L.H.; Brandão, M.G.; Santos-Filho, D.; Lopes, J.L.; Krettli, A.U. Antimalarial activity of crude extracts from Brazilian plants studied in vivo in Plasmodium berghei-infected mice and in vitro against Plasmodium falciparum in culture. Braz. J. Med. Biol. Res. 1991, 24, 1113-1123.

20. Willcox, M.; Bodeker, G.; Rasoanaivo, P.; Addae-Kyereme, J. Traditional Medicinal Plants and Malaria, 1st ed.; CRC Press: Boca Raton, FL, USA, 2004; pp. 255-270.

21. Ramazani, A.; Zakeri, S.; Sardari, S.; Khodakarim, N.; Djadidt, N.D. In vitro and in vivo anti-malarial activity of Boerhavia elegans and Solanum surattense. Malar. J. 2010, 9, 124. [CrossRef]

22. Woodford, J.; Shanks, G.D.; Griffin, P.; Chalon, S.; McCarthy, J.S. The Dynamics of liver function test abnormalities after malaria infection: A retrospective observation study. Am. J. Trop. Med. Hyg. 2018, 98, 1113-1119. [CrossRef]

23. Brown, D.D.; Solomon, S.; Lerner, D.; Rio, M.D. Malaria and acute kidney injury. Pediatr. Nephrol. 2020, 35, 603-608. [CrossRef] [PubMed]

24. Bantie, L.; Assefa, S.; Teklehaimanot, T.; Engidawork, E. In vivo antimalarial activity of the crude leaf extract and solvent fractions of Croton macrostachyus Hocsht. (Euphorbiaceae) against Plasmodium berghei in mice. BMC Complement Altern. Med. 2014, 14, 79. [CrossRef]

25. Viriyavejakul, P.; Khachonsaksumet, V.; Punsawad, C. Liver changes in severe Plasmodium falciparum malaria: Histopathology, apoptosis and nuclear factor kappa B expression. Malar. J. 2014, 13, 106. [CrossRef]

26. Das, B.S. Renal failure in malaria. J. Vector Borne Dis. 2008, 45, 83-97.

27. Abro, A.H.; Ustadi, A.M.; Younis, N.J.; Abdou, A.S.; Hamed, D.A.; Saleh, A.A. Malaria and hematological changes. Pak. J. Med. Sci. 2008, 24, 287-291.

28. Sirak, S.; Fola, A.A.; Worku, L.; Biadgo, B. Malaria parasitemia and its association with lipid and hematological parameters among malaria-infected patients attending at Metema Hospital, Northwest Ethiopia. Pathol. Lab. Med. Int. 2016, 8, 43-50. [CrossRef]

29. Pittman, R.N. Regulation of Tissue Oxygenation: Chapter 4 Oxygen Transport San Rafael (CA). Morgan Claypool Life Sci. 2011, 3, $1-100$.

30. Kumar, P.; Nagarajan, A.; Uchil, P.D. Analysis of cell viability by the MTT assay. Cold Spring Harb. Protoc. 2018. [CrossRef] [PubMed]

31. Miller, L.H.; Su, X. Artemisinin: Discovery from the Chinese Herbal Garden. Cell 2011, 146, 855-858. [CrossRef] [PubMed]

32. Yu, F.P.S.; Molino, S.; Sikora, J.; Rasmussen, S.; Rybova, J.; Tate, E.; Geurts, A.M.; Turner, P.V.; Mckillop, W.M.; Medin, J.A. Hepatic pathology and altered gene transcription in a murine model of acid ceramidase deficiency. Lab. Investig. 2019, 99, $1572-1592$. [CrossRef] 